extraction (FTOE) $24 \mathrm{~h}$ after birth in infants have reported to be associated with adverse outcomes. Near-infraredtime-resolved spectroscopy (TRS) device enables the simultaneous assessment of quantitative hemodynamics, and absolute values of $\left(\mathrm{rSO}_{2}\right)$ and cerebral bloodvolume (CBV). The purpose of our study was to determine the usefulness of both $\mathrm{rSO}_{2}$ and $\mathrm{CBV}$ measured by TRS in infants with asphyxia after birth.

Methods Twenty-six infants with asphyxia (Apgar score $<7$ at 1 min after birth) were divided into 2 groups: those with hypoxicischaemic encephalopathy (HIE; HIE group, $\mathrm{n}=5$ ) and those without hypoxic-ischaemic encephalopathy (non-HIE group, $\mathrm{n}=$ 21). $\mathrm{rSO}_{2}$ and FTOE were measured by TRS at 12, 24, 48, and $72 \mathrm{~h}$ after birth.

Results $\mathrm{rSO}_{2}$ was significantly higher and FTOE was significantly lower in the HIE group $(n=5)$ than in the non-HIE group $(\mathrm{n}=21)$ at $12,24,48$, and $72 \mathrm{~h}$ after birth. CBV was significantly higher in the HIE group $(n=5)$ than in the non-HIE $(\mathrm{n}=21)$ from $3-6 \mathrm{~h}$ after birth through all measurement time points.

Conclusions Changes in CBV occurred earlier than those in $\mathrm{rSO}_{2}$. Thus, CBV may be an early predictive parameterfor adverse outcomes in infants with asphyxia after birth.

\section{PO-0404 3D SURFACE IMAGING OF HEAD SHAPE AND HEAD DEFORMITIES IN HEALTHY NEWBORNS - A CROSS-SECTONAL STUDY}

S Ifflaender, W Burkhardt, D Konstantelos, M Rüdiger. Department of Neonatology and Pediatric Intensive Care, Medizinische Fakultät Carl Gustav Carus an der TU Dresden, Dresden, Germany

\subsection{6/archdischild-2014-307384.1050}

Background and aims Congenital cranial asymmetry is a precursor for the development of head deformities. However, early changes are often subtle and can be overlooked. Surface imaging improves detection of postnatal head deformities. The purposes of the present study were 1) to determine normative values of head shape at birth with a $3 \mathrm{D}$ laser system and 2) to identify potential risk-factors for congenital head shape abnormalities.

Methods In a cross-sectional study design healthy neonates born in a university hospital between 2/2013 and 3/2014 were scanned between 12 and $72 \mathrm{~h}$ after birth with a non-invasive laser scanner (STARScanner ${ }^{\mathrm{TM}}$ ). Normative values of established indices (Cranial Index - CI; Cranial Vault Asymmetry Index CVAI) were computed. Infants with cranial asymmetry were analysed for pre- and perinatal risk factors.

Results Scans of 1095 newborns (m557, f538; $3373 \pm 477 \mathrm{~g}$ ) were analysed. 1) Normative values of cranial measures and indices were calculated and are presented. 2) Cranial asymmetry was due to Cephalohematoma or Caput succedaneum in $4.5 \%$ of infants. In remaining infants it was not related to multiple birth, gender, gestational age, birth-presentation or delivery mode.

Conclusions The present study provides normative cranial data from 3D surface scans in a cohort of healthy newborns in the first $72 \mathrm{~h}$ of life. This allows a precise classification of head shape and an improved identification of abnormalities. In contrast to previous investigations, head asymmetry was not associated with any prenatal and perinatal factors. Long term consequences of congenital head shape abnormalities need to be further investigated in longitudinal studies.

\section{PO-0405 ERYTHROPOIETIN CONCURRENT WITH HYPOTHERMIA FOR NEONATAL HYPOXIC ISCHAEMIC ENCEPHALOPATHY}

${ }^{1}$ I Tofé Valera, ${ }^{2}$ MD Cañete Vazquez, ${ }^{1}$ MD Ruiz Gonzalez, ${ }^{1} J M$ Guzman Cabañas, ${ }^{1} P$ Jaraba Caballero, ${ }^{1} \mathrm{MD}$ Huertas Muñoz, ${ }^{1} \mathrm{MV}$ Rodriguez Benitez, ${ }^{1} \mathrm{MD}$ Ordoñez, ${ }^{1} \mathrm{MC}$ de la Camara, ${ }^{1} \mathrm{MJ}$ Parraga Quiles, ${ }^{1} \mathrm{R}$ Cañete Estrada. ${ }^{1}$ Pediatrics. Hospital Reina Sofia/IMIBIC, Hospital Reina SofíalIMIBIC, Córdoba, Spain, ${ }^{2} I M I B I C$, Group PAIDI CTS-329. IMIBIC, Córdoba, Spain

\subsection{6/archdischild-2014-307384.1051}

Background Hypothermia (HT) within the first six hours of life provides neuroprotection in newborns with hypoxic ischaemic encephalopathy (HIE). Erythropoietin (EPO) has been found to enhance erythropoiesis and exert anti-inflammatory, immunomodulatory, antiapoptotic and neuroprotective effects.

Aim To evaluate the efficacy and safety of EPO therapy in neonates with HIE.

Methods 15 newborns with HIE displaying no congenital malformations of life-threatening pathologies, received treatment with $\mathrm{HT}(\mathrm{n}=3)$, EPO $(\mathrm{n}=3)$ or HT+EPO $(\mathrm{n}=9)$. Once informed consent had been obtained, rhEPO was iniciated subcutaneously in the first $24 \mathrm{~h}$ of life at a dose rate of $400 \mathrm{UI} / \mathrm{k} /$ q48h/2weeks.

Results Baseline clinical data for the three study group are shown in figure1. No intergroup differences were recorded for incidence of clinical and electrical seizures over the first $24 \mathrm{~h}$. Neurological examination at 12 months revealed a reduction in death rates and in severe disability rates $(\mathrm{p}=0,021)$. Brain damage biomarkers level were lower. No complications were recorded following treatment with rhEPO. Data were analysed using the ChiSquare test for qualitative variables and the kruskal-Wallis test for quantitative variables; the level of significance was set at $\mathrm{p}<0.05$.

Conclusions Hypothermia has been demonstrated the only therapeutic option against brain damage in newborns with HIE but rhEPO is an effective, safe, affordable cytokine with potential neuroprotective effects. It could be used in combination with HT for treating HIE. Further research are required to define the optimum treatment in these patients.

\section{Abstract P0-0405 Table 1 Baseline characteristics of enrolled} infants

\begin{tabular}{|c|c|c|c|c|}
\hline & \multicolumn{3}{|c|}{ GROUPS TREATMENT } & \multirow[b]{2}{*}{$P$} \\
\hline & HT $(n=3)$ & EPO $(n=3)$ & H T +EPO (n=9) & \\
\hline Gender (M/F) & $2 / 1$ & $0 / 3$ & $6 / 3$ & 0.117 \\
\hline GA (weeks) & $39.33 \pm 1.52$ & $36.66 \pm 4.93$ & $39.66 \pm 1.22$ & 0.192 \\
\hline Birth w eight (g) & $3722.33=329.5$ & $2333.33 \pm 784.60$ & $3243.11=308.50$ & $0.005^{*}$ \\
\hline Apgar score (1 min) & 2 & 1 & 2 & 0.816 \\
\hline$(5 \mathrm{~min})$ & 3 & 2.66 & 3.66 & 0.606 \\
\hline$(0 \mathrm{~min})$ & 5 & 5.33 & 5.22 & 0.937 \\
\hline pH acid & $6.88 \pm 0.10$ & $6.80=0.00$ & $6.86 \pm 0.17$ & 0.466 \\
\hline Base déficit & $22.67 \pm 3.51$ & $22.63 \pm 1.09$ & $17.78=8.99$ & 0.490 \\
\hline Lactate acid $(\mathrm{mmol} / \mathrm{L})$ & $17.40=3.12$ & $18.30=2.94$ & $16.75 \pm 4.22$ & 0.834 \\
\hline Delivery mode (V/C) & $0 / 3$ & $0 / 3$ & $1 / 8$ & 0.700 \\
\hline Sentinel event $(\%)$ & 100 & 100 & 100 & 1 \\
\hline Sarnat grade (II/III) & $1 / 2$ & $3 / 0$ & $5 / 4$ & 0.745 \\
\hline Glu cose $(\mathrm{mg} / \mathrm{dL})$ & $79 \pm$ & $64 \pm$ & $151=$ & 0.220 \\
\hline$T^{2}(P)$ & $35.8 \pm$ & $36.2 \pm$ & $34.1=$ & $0.044^{*}$ \\
\hline
\end{tabular}

\section{P0-0406 THE CONTRIBUTION OF PROTHROMBOTIC DISORDERS TO PERINATAL ARTERIAL ISCHAEMIC STROKE (PAIS): A STUDY OF CASE-CONTROL PARENT-CHILD PAIRS}

1J Arnaez, ${ }^{2} \mathrm{~A}$ Martin-Ancel, ${ }^{2} \mathrm{~V}$ Tenorio, ${ }^{2} \mathrm{G}$ Arca-Diaz, ${ }^{2} \mathrm{~A}$ Garcia-Alix. ${ }^{1}$ Neonatology, University Hospital of Burgos, Burgos, Spain; ${ }^{2}$ Neonatology, Agrupacio Sanitaria Hospital Sant Joan de Déu-Hospital Clinic, Barcelona, Spain

10.1136/archdischild-2014-307384.1052 
Background Prothrombotic risk factors (PRF) are suggested to be involved in the pathogenesis of PAIS. However, most of published studies are retrospective, they vary in the PRF tested and parents are not usually investigated.

Objective To determine the impact of parental and infant thrombophilia on neonatal cases diagnosed of PAIS in a prospective case-control study.

Methods Factor V (G1691A mutation), prothrombin G20210A variant, MTHFR C677T genotype, antithrombin, protein C, protein S, lipoprotein (a), homocystein (Hcy) and anticardiolipin antibodies were investigated in 45 infant-parent pairs with PAIS and in 85 controls. Blood samples were drawn within the first week of life.

Results All thrombophilic factors investigated were similar or even less frequent among patients with PAIS and their parents compared to controls. The most frequent PFRs were Hcy $>11$ and MTHFR homozygosity in cases $(7.5 \%$ and $5.3 \%$, respectively) and in controls (24.4\% and $13.1 \%$, respectively). Thirteen neonates diagnosed of PAIS (28.9\%) had at least 1 PFR, compared to 39 subjects $(44.3 \%)$ in the control group (OR/95\% CI, $0.51 / 0.23$ to 1.10$)$ ( $p<0.001)$. Twenty three mothers of infants with PAIS (51.1\%) were positive for thrombophilia markers, compared to $49(55.7 \%)$ controls $(p=.617)$. In 8 mother-infant pairs $(17.8 \%)$, at least 1 PFR could be identified for either mother or infant, compared to 19 controls $(21.6 \%)$. Fifteen neonates with stroke $(33.3 \%)$ had at least one PFR compared to the 57 subjects $(64.8 \%)$ in the control group $(\mathrm{p}<$ 0.001).

Conclusion Our data do not support that PFR play a major role in PAIS.

\section{PO-0407 PERINATAL FACTORS AND PERINATAL ARTERIAL ISCHAEMIC STROKE (PAIS): A PROSPECTIVE CASE-CONTROL STUDY}

${ }^{1} \mathrm{~A}$ Arnaez, ${ }^{2} \mathrm{G}$ Arca-Diaz, ${ }^{2} \mathrm{~A}$ Martin-Ancel, ${ }^{2} \mathrm{~T}$ Agut, ${ }^{2} \mathrm{M}$ Camprubí, ${ }^{2} \mathrm{~A}$ García-Álix. ${ }^{1}$ Neonatology, University Hospital of Burgos, Burgos, Spain; ${ }^{2}$ Neonatology, Agrupacio Sanitaria Hospital Sant Joan de Déu-Hospital Clinic, Barcelona, Spain

\subsection{6/archdischild-2014-307384.1053}

Background Perinatal factors (PF) have been implicated in the pathogenesis of PAIS. Hypoxia has been suggested to be involved as a potential cause of AIS although prospective case-control studies are still warranted.

Objective To determine the impact of PF on neonatal cases diagnosed of PAIS in a prospective case-control study.

Methods 45 neonates were diagnosed of PAIS within four weeks of life and 85 controls were investigated for the following PF: retarded intrauterine growth restriction, sentinel event, epidural and general anaesthesia, presentation at delivery, type of delivery (vaginal, instrumental, emergency caesarean section), abnormal cardiotocographic monitoring, Apgar score at 1 and $5 \mathrm{~min}$, arterial umbilical cord $\mathrm{pH}<7.0$ and $<7.20$, and need of advanced resuscitation.

Results The univariate analysis indicated the following associations with PAIS: emergency caesarean section $(48.9 \%$ vs $14.8 \%$; $\mathrm{p}<0.001)$; Apgar score at $1 \mathrm{~min}<7(22.2 \%$ vs $4.6 \% ; \mathrm{p}=$ $0.005)$ and $<5(15.6 \%$ vs $1.1 \% ; \mathrm{p}=0.002)$; arterial cord $\mathrm{pH}$, mean \pm SD $7.19 \pm 0.12(\mathrm{CI} 95 \% 7.15,7.23)$ in infants with PAIS compared to $7.25 \pm 0.1(7.23,7.27)$ in controls $(\mathrm{p}=$ $.005)$; arterial cord $\mathrm{pH}<7.20$ (45.2\% vs $17.8 \%$; $\mathrm{p}=0.006)$.

A multivariate analysis did not show any independent factor associated to PAIS, except for arterial cord $\mathrm{pH}<7.20$ (OR 2.89,
CI95\% 1.01, 8.31). Emergency caesarean section and Apgar score $<5$ at $1 \mathrm{~min}$, showed a tendency to be associated with PAIS but without statistical significance: OR 2.61 (95\% CI 0.66, 10.2) and 10.02 (CI95\% 0.46, 215.8).

Conclusion Our data indicate that PF do not appear to play a major role in PAIS.

\section{PO-0408 CAUSES AND OUTCOME OF NEONATAL CONVULSIONS}

F Kamoun, M Hsairi, L Sfaihi, S Ben Ameur, I Maaloul, TH Kamoun, M Hachicha. Pediatrics Department, Hedi Chaker Hospital, Sfax, Tunisia

\subsection{6/archdischild-2014-307384.1054}

Background and aims Convulsions occur more frequently in the neonatal period than at any other time.

Aims Study the clinical, etiological, therapeutic aspects and the outcome of neonatal convulsions.

Methods We report a retrospective analysis of 51 cases of neonatal convulsions between 2009 and 2013.

Results The sex-ratio was 1.1. Prematurity was found in 8 patients. The Apgar score was lower or equal to 7 in the first minute in 16 cases. The average age of the first convulsion was 9 days. The motive of admission was convulsion in 35 cases (66\%). It was a convulsive status epilepticus in 4 cases. The neurological examination was pathological in 27 cases. A metabolic balance sheet, lumbar puncture were realised in every case, cranial ultrasound scan (34 cases), cerebral CT scan (19 cases), electroencephalography (29 cases) and MRI (16 cases). Causes of neonatal convulsions were: hypoxic-ischaemic encephalopathy (13 cases), hypoglycemia (7 cases), hyponatraemia (6 cases), hypocalcemia (4 cases), pyridoxine dependency (1 case), meningitis (5 cases), hypertension (1 case), ischaemic stroke (1 case), cerebral haemorrhage (3 cases), anomaly of the urea cycle (1 case), West syndrome (2 cases) and idiopathic neonatal convulsions ( 7 cases). The treatment was etiological in 23 cases. The outcome was favourable in 37 cases, 4 patients died and variable sequelae were found in 10 cases.

Conclusion This study emphasises the variability of aetiology of neonatal convulsions and the necessity of the etiological diagnosis on which will depend the prognosis.

\section{PO-0409 WITHDRAWN}

\section{PO-0410 PROPYLENE GLYCOL (PG) DETECTION BY BRAIN MAGNETIC SPECTROSCOPY (MRS) IN INFANTS WITH NEONATAL ENCEPHALOPATHY}

${ }^{1} \mathrm{~K}$ Povazai, ${ }^{2} \mathrm{R}$ Johnstone, ${ }^{2} \mathrm{~N}$ Byrne, ${ }^{2} \mathrm{~J}$ Ashmore, ${ }^{3} \mathrm{D}$ Azzopardi, ${ }^{4} \mathrm{MM}$ U-King-Im, ${ }^{4} \mathrm{~A}$ Siddiqui, ${ }^{1} \mathrm{AB}$ Kapetanakis, ${ }^{2} \mathrm{G}$ Charles-Edwards. 'Neonatal Medicine, Evelina London Children's Hospital, London, UK; ${ }^{2}$ Medical Physics, King's College London, London, UK; ${ }^{3}$ Neonatal Medicine, King's College London, London, UK; ${ }^{4}$ Neuroradiology, Guy's and St Thomas NHS Foundation Trust, London, UK

\subsection{6/archdischild-2014-307384.1055}

Background PG is a commonly used excipient contained in several medications to control neonatal seizures (Phenobarbitone (PhB) (79\%) Phenytoin (Ph) (40\%) and Clonazepam). On MRS the appearance of a doublet at $1.1 \mathrm{ppm}$ in some spectra is attributed to PG. The lower safe level of short term exposure to PG 